\title{
Spatial distribution of Guaiacum sanctum (Zygophyllaceae) seedlings and saplings relative to canopy cover in Palo Verde National Park, Costa Rica
}

\author{
Eric J. Fuchs ${ }^{1,2}$, Tatiana Robles ${ }^{3}$ \& James L. Hamrick ${ }^{1}$ \\ 1.Plant Biology Dept. University of Georgia, Athens, GA. 30602, USA; hamrick@plantbio.uga.ed \\ 2. Escuela de Biología, Universidad de Costa Rica,2060 San José, Costa Rica; e.j.fuchs@gmail.com, eric.fuchs@ucr.ac.cr \\ 3. Escuela de Ciencias de la Educación, Universidad Estatal a Distancia, San José, Costa Rica; ttrobles@gmail.com
}

\author{
Received 14-VI-2012. Corrected 30-X-2012. Accepted 19-XI-2012.
}

\begin{abstract}
Distribución espacial de Guaiacum sanctum (Zygophyllaceae) en relación con la cobertura de dosel en el Parque Nacional Palo Verde, Costa Rica. The spatial distribution of individuals is a fundamental property of most species and constitutes essential information for the development of restoration and conservation strategies, especially for endangered plant species. In this paper we describe the spatial distribution of different size classes of the endangered tropical tree Guaiacum sanctum and the effect of canopy cover on spatial aggregation. Adult G. sanctum were located and mapped in a 50ha plot in Palo Verde National Park, Costa Rica. Seedlings, saplings and juveniles were mapped to the nearest centimetre and permanently marked in three 50x50m subplots. Within each subplot spatial aggregation was assessed using Ripley's K statistic and canopy opening readings were performed every $5 \mathrm{~m}$ using a densitometer. Kriging spatial interpolation and Monte Carlo simulations were used to determine if average canopy cover differed among size classes. Individuals of G. sanctum were spatially aggregated at all size classes with seedlings being the most frequent size class in all subplots. Seedlings were found predominantly in areas with significantly higher canopy cover. In contrast, juveniles were more likely found in areas with higher light availability. The high number of seedlings, saplings, and juveniles relative to adults suggests that populations of G. sanctum in PVNP are expanding. Light availability and canopy structure are important factors shaping the spatial distribution of this species. The contemporary demographic structure of $G$. sanctum is dependent on forest gap dynamics and changes in human disturbance during the past 25 years. Rev. Biol. Trop. 61 (3): 1521-1533. Epub 2013 September 01.
\end{abstract}

Key words: gap dynamics, bird dispersal, microenvironment selection, desiccation avoidance.

Spatial distribution and patterning of plants is an important characteristic of communities and is a fundamental property of most species. Hutchinson (1953) determined that at least five causal factors shape the spatial pattern of plant species: 1) environmental factors such as nutrients or light availability, 2) reproductive factors including propagule dispersal and seasonality, 3) interspecific or social factors such as territoriality, predation and competition, 4) intraspecific components such as competition and density dependent factors and 5) stochastic variation in any of these causal factors. Evidence for micro-environmental heterogeneity
(Forget et al. 1999, Palmiotto et al. 2004), localized seed dispersal (Russo \& Augspurger 2004) and density-dependent factors affecting spatial distribution have been previously determined for many tree species (Gilbert et al. 1994, Grau 2000, John et al. 2002, Lambers et al. 2002, Schupp 1992), with some authors supporting a combination of multiple factors (Itoh et al. 1997). Many authors have shown that most tropical tree species have aggregated spatial distributions (Armesto et al. 1986, Condit et al. 2000, He et al. 1997, Hubbell 1979, Okuda et al. 1997), generally attributed to a combination of dispersal limitation 
and micro-site variation. Light availability and gap-phase dynamics have also been described as important factors shaping the spatial distribution and regeneration patterns of tropical trees (Denslow 1987). In tropical dry forests, light availability is directly related to seedling mortality and recruitment patterns. Areas with low canopy cover generally have few seedlings due to increased desiccation (Gerhardt 1996). Therefore, light availability should be taken into account when studying the spatial distribution and regeneration of tropical dry forest tree species. Condit et al. (2000) showed that rare species are generally more aggregated than common species, and Hubbell \& Foster (1986) proposed that light availability was the main proximal factor shaping aggregated distributions, with a significant proportion of rare or endangered species in the heliophyle category. For many endangered species, necessary information on their spatial distribution and the effect of abiotic factors on spatial patterns is lacking.

Guaiacum sanctum (Zygophyllaceae) is a slow growing tropical and subtropical dry forest tree, distributed from Southern Central America to Northern Mexico and Florida, and throughout the Greater Antilles (Holdridge \& Poveda 1975). This species, also known as Lignumvitae, has been heavily exploited for its hard wood and medicinal value. It's extremely dense wood was popularly used for the construction of propeller shafts on steamships. Additionally, for over five centuries, adecoction of Guaiacum sanctum was believed to cure syphilis (Voeks 2004). Therefore, most populations of G. sanctum were decimated by the end of the 19th century with a few remnant and highly isolated populations remaining in Mexico, Central America, and the Florida Keys. In Costa Rica, G. sanctum is distributed throughout the dry forests of the Northwest Pacific coast (Fuchs \& Hamrick 2010a). Tropical dry forests are the most endangered biome in the Neotropics with less than $0.1 \%$ of its original cover remaining (Janzen 1988), and currently many sites suitable for $G$. sanctum populations have been transformed to agricultural fields or pastures. Therefore, extant populations of $G$. sanctum in Costa Rica are rare, and generally restricted to national parks or reserves that continue to be menaced by habitat loss, fire or exploitation (Oldfield et al. 1998). Because of its restricted distribution and reduced population sizes, G. sanctum is now included in Appendix I of the CITES convention (CITES 2000) and is also termed "Endangered" in the World List of Threatened Trees (Oldfield et al. 1998).

Recent work on $G$. sanctum showed high levels of intra population genetic diversity and a lack of fine-scale genetic structure (Fuchs \& Hamrick 2010b), congruent with high rates of seed dispersal and seed mixture from multiple maternal plants. Based on these results, we hypothesize a random spatial distribution of $G$. sanctum seedlings. As a typical species of tropical dry forest, canopy cover and desiccation avoidance should play an important role in its recruitment and survival, therefore, we expect that canopy cover should have a measurable effect on the spatial distribution of this species. Finally, differences in spatial patterns between size classes may be used to obtain important information on the regeneration requirements of this species (Nichols et al. 1999, Okuda et al. 1997, Yamada \& Suzuki 1997). In this study we described the spatial distribution of different size classes of G. Sanctum in a dry forest from North-western Costa Rica. We also used spatial statistics to analyse the effect of light availability on regeneration and the spatial distribution of age classes of this endangered tropical tree.

\section{MATERIALS AND METHODS}

Study site: This study was conducted within Palo Verde National Park (PVNP) in the lower Tempisque River basin on the Pacific lowlands of North-western Costa Rica $\left(10^{\circ} 21^{\text {' }}\right.$ $\left.\mathrm{N}-85^{\circ} 21^{\prime} \mathrm{W}\right)$. Upland portions of the $19000 \mathrm{ha}$ park are mainly composed of dry tropical forest on limestone outcrops, with mean annual rainfall below $1500 \mathrm{~mm}$ and mean annual temperature of $30^{\circ} \mathrm{C}$. The area is characterized 
by an extended dry season from December through April and a wet season from May to November. Palo Verde National Park has areas of continuous forest, which have been preserved from forest fires or logging for the last 25-30 years. One of the last remaining populations of Guaiacum sanctum in Costa Rica occurs on its dry limestone slopes. Soil type on these hills isof the Inceptisols order (lithic ustropept subgroup), which is a well-drained low fertility soil with a shallow calcic horizon (Vaughan et al. 1982).

Spatial distribution: In 2003, a 50ha plot (i.e. $1 \mathrm{~km} \times 500 \mathrm{~m}$ ) was created on the Southwestern slope of "Guayacan" hill in PVNP (Fig. 1). All adult G. sanctum within the plot were marked and mapped using a GPS and densities and spatial distribution of $G$. sanctum adults were determined. To determine the density and spatial distribution of seedling and juvenile G. sanctum, three permanent 50x50m subplots were established in areas of high $G$. sanctum density within the 50ha plot (Fig. 1).
The three sub-plots have recent tree-falls (i.e. within 5-10 years) and hence vary in canopy structure. Within these subplots all G. sanctum were mapped to the nearest centimetre using tape measures and were marked with permanent aluminium or plastic tags. Height $(h)$ and diameter at ground level (DGL) were determined for all individuals within the subplots; DBH was also measured for individuals with $\mathrm{DBH}>5 \mathrm{~cm}$. All data were collected during the wet season, between June and December 2004.

Individuals within all three subplots were grouped into five height classes or life stages: seedlings $(h<15 \mathrm{~cm})$, saplings $(15<h<30 \mathrm{~cm})$, juveniles $(30 \mathrm{~cm}<h<2 \mathrm{~m})$, sub-adults $(2<h<5 \mathrm{~m})$ and adults $(h>5 \mathrm{~m})$. Height is used as a proxy for age, since no prior information exists on growth rates for this species. Size and height will be used interchangeably. Spatial patterns for each size class were tested using Ripley's $K(t)$ function (Ripley 1977). This function describes two-dimensional spatial distribution patterns. The $K(t)$ function tallies the expected number of points that fall within a circle of

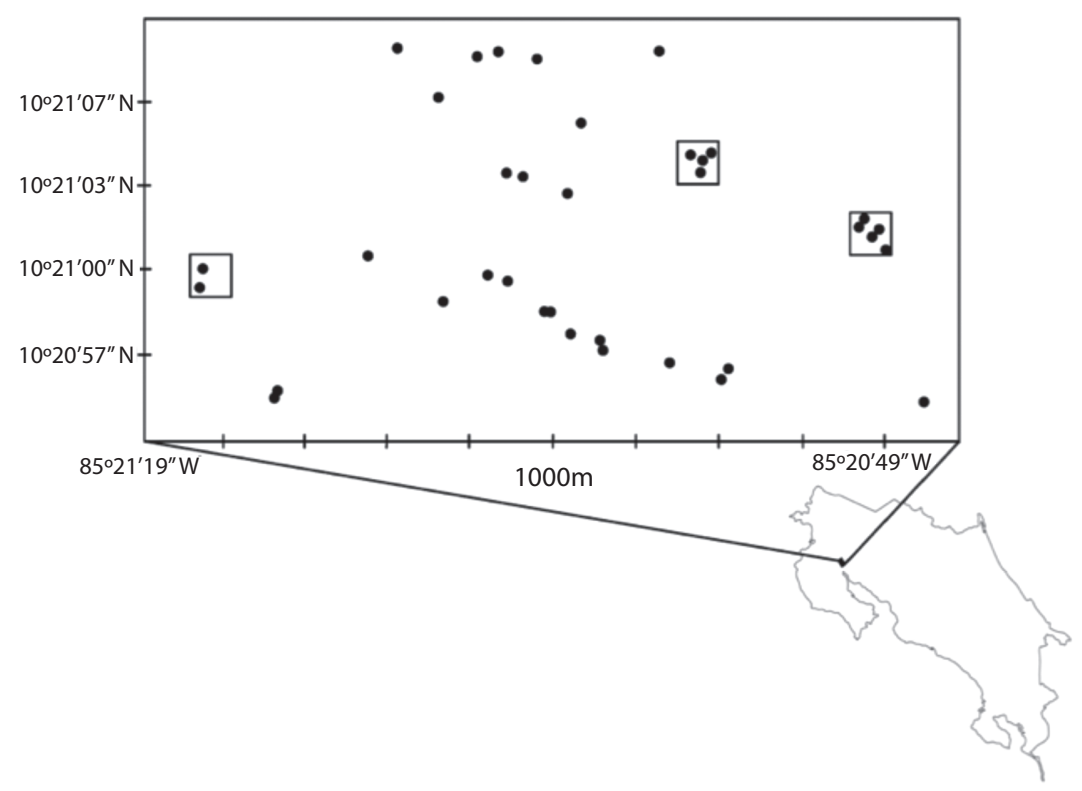

Fig. 1. Adult $G$. sanctum individuals within the 50 ha plot located within Palo Verde National Park. Adults are depicted as black dots, subplots are shown as squares. A rectangle within Costa Rica's map depicts the approximate location of the 50ha plot. 
radius $t$ at any point in two-dimensional space based on the Poisson distribution. That is, $K(t)$ shows the proportion of points that fall within each $t$ distance class. The $L(t)$ square-root transformation of $K(t)$ :

$$
L(t)=\sqrt{\frac{K(t)}{\pi}}-t
$$

is generally preferred since it linearizes the function and homogenizes confidence interval widths, which allows easier interpretation (Diggle 2003). Graphical representation of the $L(t)$ function may be interpreted as follows: complete random distribution of points if $L(t)$ does not deviate from zero; aggregated spatial distribution $L(t)>0$; and $L(t)<0$ suggests a regular distribution. For each subplot, we analyzed the spatial distribution of the three youngest size classes (juveniles and sub-adults were pooled due to a low number of individuals in the latter category) at $1 \mathrm{~m}$ intervals, for $t$ distances ranging from 1 to $25 \mathrm{~m}$ (i.e. half the length of the subplot). Due to their low densities, the spatial pattern of adult trees was analyzed by means of Ripley's K function using data for the entire 50ha plot.

We analyzed the spatial distribution between different size classes with Ripley's second order analysis (Ripley 1976). This function describes the spatial relationship between two size classes (i.e. aggregated, random or repulsion). Categories are aggregated when individuals from different groups are found at closer distances than expected by random. Repulsion is the contrary effect, when individuals from different size classes are rarely found in close proximity. If no pattern is observed, the distribution of the two size classes relative to one another is considered random. We examined the spatial relationship between all pairwise comparisons of different size classes by means of the $L(t)$ function. A $95 \%$ confidence envelope was created for all $L(t)$ functions by means of 10000 Monte Carlo simulations, where the position of individuals is randomly shifted in a toroidal plane. All calculations were performed using the SpatStat library in R (R Development Core Team 2008,
Turner \& Baddeley 2005). To determine if the average distance to an adult varies with size, we measured the Euclidean distance of every individual within a sub-plot to every adult within the sub-plot. Average distances to the nearest adult and the second and third nearest adult were calculated for each size class and averaged across plots.

Canopy cover: To determine the effect of canopy cover on seedling and sapling abundances, we created a two-dimensional map of canopy cover for each subplot. We estimated canopy openness on a $5 \times 5 \mathrm{~m}$ grid over each subplot taking measurements at each grid node using a spherical convex densitometer. We took four readings in orthogonal directions for each node and three measurements were conducted during the day: 07:00 am, 12:00 pm and 17:00 $\mathrm{pm}$. Densitometer readings were transformed to percent canopy opening following instrument directions and average all node measurements for further analysis. To estimate canopy opening for each marked individual, a canopy cover map was created using Ordinary Kriging interpolation technique implemented by the GeoR library (Ribeiro \& Diggle 2001) in R (Ihaka \& Gentleman 1996). A canopy opening index (COI: \% canopy opening) was estimated for each marked $G$. sanctum individual in each subplot using this canopy cover map.

We compared the average canopy opening index of different size classes from those expected by a null distribution produced by re-sampling random points from each subplot. Random locations from each subplot where drawn based on a uniform probability distribution, and their canopy opening index was determined using a canopy cover map estimated via kriging. For each size category, the number of random points drawn was equivalent to the number of observed individuals. An average canopy opening index was estimated for the simulated points and was compared to the average canopy opening index of observed individuals. This process was repeated 10000 times for each size category and $95 \%$ confidence intervals were built around the mean of 
simulated values. The average canopy cover of each size class was statistically different than the random expectation if the mean did not overlap with the confidence interval.

\section{RESULTS}

A total of 35 adults were marked within the 50ha plot (i.e. 0.7 adults per hectare; Fig. 1.). Adults had an average DBH of $35 \mathrm{~cm}( \pm 8.2)$ with a skewed distribution towards lower diameters. Adults were spatially aggregated forming clumps of two to four individuals within $\gg 20 \mathrm{~m}$ of one another (data not shown).

A total of 2155 G. sanctum individuals were marked in the three sub-plots. Over $65 \%$ of these individuals belonged to the seedling category: saplings and juveniles represent $16.7 \%$ and $17.6 \%$ of the entire sample, respectively. Adults (11 individuals) and sub-adults (seven individuals) comprised less than $1 \%$ of the total sample. The percentage of individuals in different size classes varied significantly among subplots $\left(\mathrm{G}^{2}=445.61, \mathrm{df}=8, \mathrm{p}<0.001\right.$; Fig. 2.) with juveniles being the most common size class in sub-plot three. Overall, the average seedling to adult ratio was $106.33( \pm 49.38)$. Sapling and juvenile to adult ratios were 35.5 $( \pm 6.22)$ and $43.9( \pm 20.56)$, respectively. There was a two-fold decline in the number of juveniles relative to seedlings.

Seedlings, saplings and juveniles were distinctly clumped (i.e. $L(t)>0$; Fig. 3.). Seedlings have the highest aggregation across all distances, and juveniles are more aggregated than saplings. The spatial distribution of saplings becomes random at higher spatial distances for all three subplots, a trend not observed for the other size categories (Fig. 3.). Across all subplots, seedlings, saplings and juveniles are always aggregated with each other (data not shown). Seedlings, saplings and juveniles are randomly distributed relative to adults, with seedlings showing sporadic departures from random (data not shown). Average distance to the nearest adult increases significantly with size (Fig. 4; $F=159.73$, $p<0.001$; box-cox transformation $\lambda=0.2$ ). The average distance of seedlings to the nearest adult is $7.75 \mathrm{~m}$ $( \pm 0.144)$, while for saplings and juveniles; it is $13.28 \mathrm{~m}( \pm 0.484)$ and $14.50( \pm 0.470)$ meters, respectively.
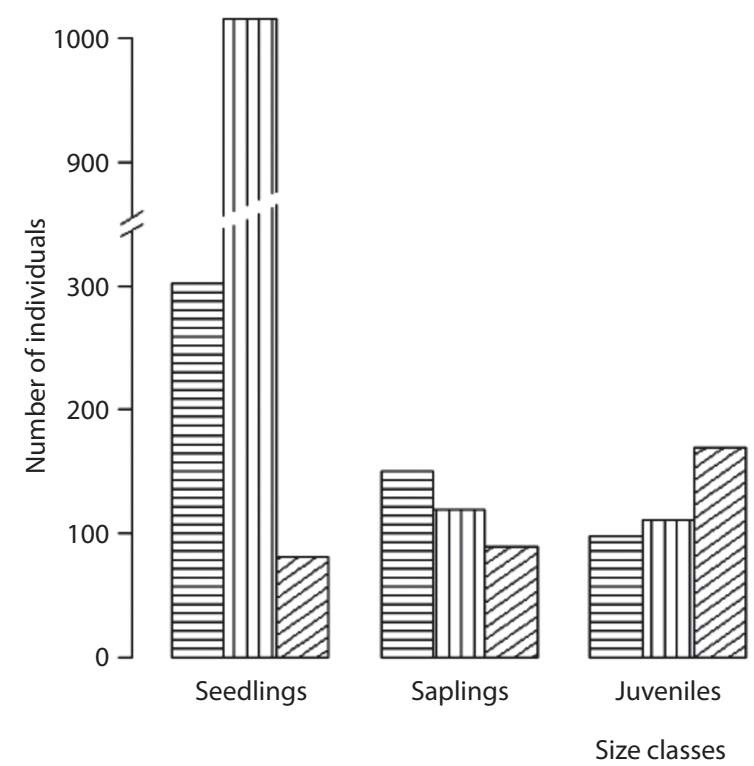

Fig. 2. Number of Guaiacum sanctum individuals in size classes found in each of the 50x50m subplots in Palo Verde National Park, Costa Rica. 

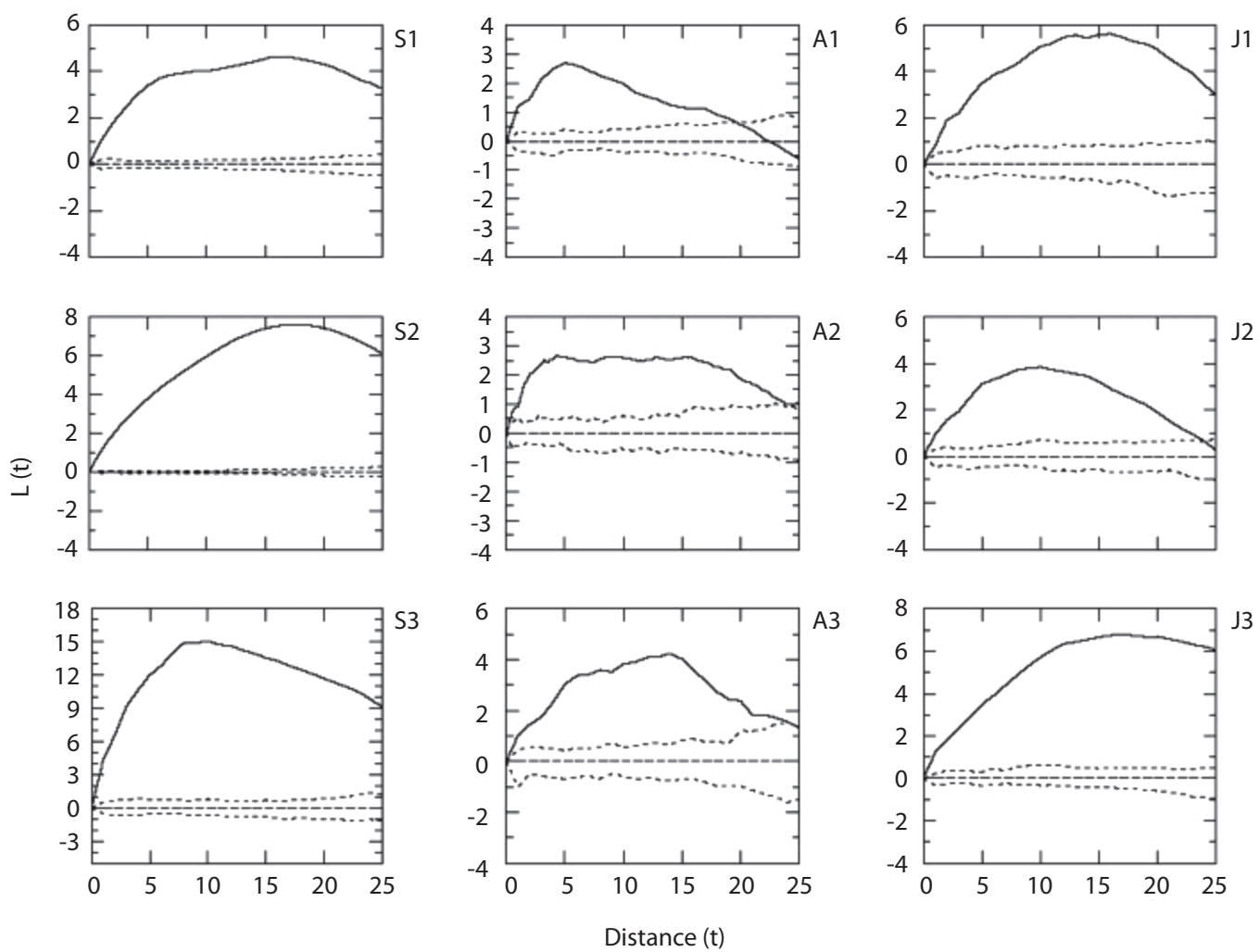

Fig. 3. Ripley's $L(t)$ function for seedlings (S), saplings (A) and juveniles $(\mathbf{J})$. Solid line depicts the $L(t)$ function for each $t$ distance class, $95 \%$ confidence intervals are shown as dotted lines. Results for each subplot are shown in consecutive lines. Letters and numbers represent size class categories and subplot numbers, respectively.

Seedlings tend to be found in areas with dense canopy cover with an average canopy opening index (COI) of 39.7\% $( \pm 0.25)$. Conversely, juveniles occur more commonly in canopy openings (Fig. 5.); the COI for juveniles is $58.2 \%( \pm 0.63)$. Sapling distribution in reference to light availability does not differ from random expectations $(\mathrm{COI}=49.1$; Fig. 5). Overall, a positive relationship between size class and light availability is observed (Spearmans $\mathrm{r}=0.76, \mathrm{p}<0.001$ ), with larger size classes more common in areas with higher light availability. Average canopy opening differs between size classes.

\section{DISCUSSION}

Populations of $G$. sanctum in PVNP are characterized by highly skewed size distributions, with disproportionate numbers of young plants and few representatives in the sub-adult and adult categories. This distribution is typical of expanding populations of long-lived species with slow growth rates (Korning \& Balslev 1994, Zuidema \& Boot 2002, Sagar \& Singh 2004). A preliminary study with a similar plot system (0.7ha vs. 0.75ha) conducted by Ribbens (1990 Tropical Biology course, OTS 90-1), showed a size class distribution skewed towards seedlings and saplings, but lacked individuals in the juvenile category. Although it was previously suggested that regeneration of $G$. sanctum in PVNP is almost negligible (Jiménez 1993), both studies (OTS course and ours) are consistent with population growth. Since 1975, PVNP forests have been protected from harvesting and fires. During the first half of the 20th century, 

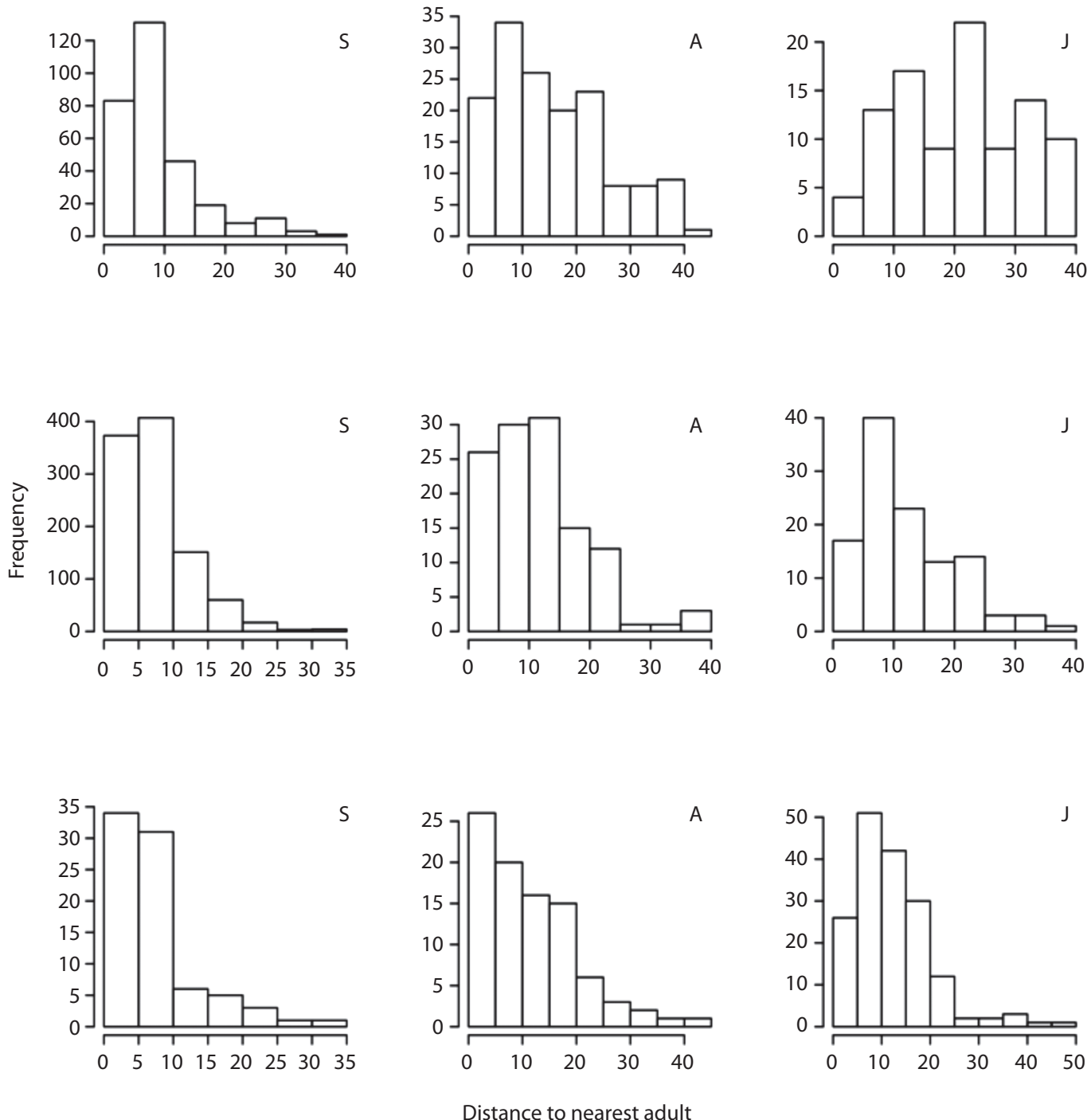

Fig. 4. Distance between seedlings (S), saplings (A) and juveniles $(\mathbf{J})$ and the nearest adult $G$. sanctum tree. Results for all three subplots are shown in consecutive lines.

timber extraction occurred in most of PVNP and fires were relatively common. It is likely that during this time, many adult and sub-adult G. sanctum were removed by logging. This could have impacted the reproductive success of the population, by reducing the number of individuals recruiting into younger size categories. Seedlings, saplings and juveniles are sensitive to fire, while adults and sub-adults are more resistant (Otterstrom et al. 2006).
Seasonal fires tend to reduce the number of individuals in younger cohorts of climax tropical tree species, and repeated fires (i.e. within 15 years) increase local extinction probabilities of many climax tree species (Slik \& Eichhorn 2003). Fires in Palo Verde are generally anthropogenic in origin, although lightning strikes occur infrequently. Most adults in our plots have large fire-scars (EJF personal observation), suggesting that this site experienced fires 


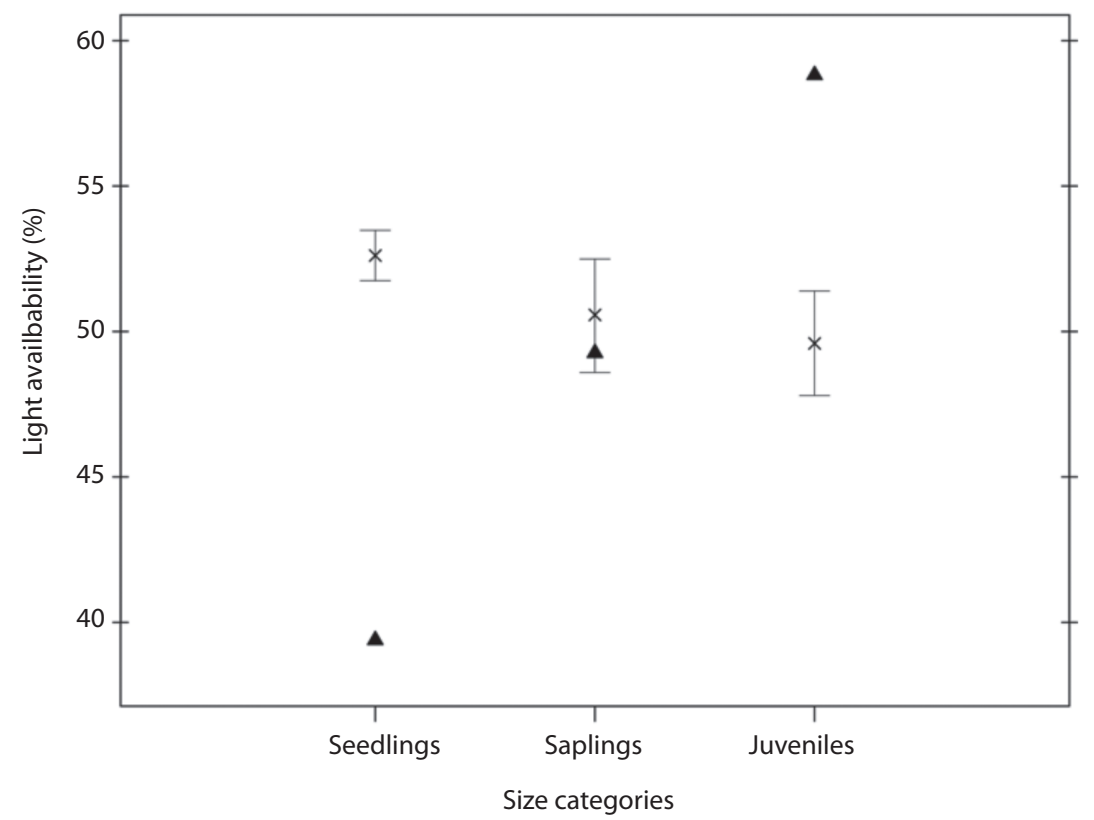

Fig. 5. Monte Carlo simulation for light availability (Canopy Opening Index, COI) of different size classes of G. sanctum. Average canopy opening (\%) is depicted by a solid triangle. The averages of Monte Carlo simulations are shown with a "x"surrounded by $95 \%$ confidence intervals.

in the relatively recent past. After PVNP was established (1978), reproduction from remaining adults began to generate a pool of seedlings and saplings. Otterstrom et al. (2006) showed that regeneration of $G$. sanctum is greatly increased in post-fire treatments. Additionally, sub-adults spared during logging may have become reproductive, increasing the number of progeny produced. Insufficient time had passed for new recruits to contribute significantly to the juvenile size class by the time of Ribbens (1990) study. However, two decades later, there is not a noticeable gap of individuals between the sapling and juvenile size classes, but there are still a low number of sub-adults and adults. Judging from the changes seen in age structure since PVNP was created, our data indicates that this population is actively growing, and that within a few decades, sub-adults and adult numbers will increase.

Spatial genetic structure (SGS) data from this population suggests ample mixing of seeds and high levels of seed dispersal (Fuchs \& Hamrick 2010b), which should result in a random distribution of propagules. However, contrary to expectations, G. sanctum individuals in PVNP are spatially aggregated at all size classes, with more aggregation in the seedling category. Spatial aggregation may occur due to two non-mutually exclusive processes: localized seed dispersal (Howe \& Smallwood 1982, Barot et al. 1999, Bleher \& Bohning-Gaese 2001, Russo \& Augspurger 2004) and the nonrandom distribution of microhabitats suitable for germination, establishment and growth (Forget et al. 1999, Silla et al. 2002, Souza \& Martins 2004). Localized seed dispersal has been proposed as a major factor contributing to aggregated distributions, with evidence in animal and wind dispersed species (Nathan \& Muller-Landau 2000, Greene et al. 2004). Howe (1989) defined bird dispersed species as "scatter-dispersed", meaning they recruit as isolated individuals with random or overdispersed distributions. G. sanctum has ornithochorous fruits (Wendelken \& Martin 1987), whose seeds are dispersed by a large array of frugivorous birds, the most common species 
observed actively foraging on G. sanctum were: Trogon melanocephalus, Trogon elegans, Tityra semifasciata, Eumomotus momota, Pitangus sulphuratus and Calocitta formosa (EJF pers. obs). These birds generally swallow the entire seed, either during flight (i.e. Trogons) or while foraging at the tree (i.e. Tityras and Magpiejay's), suggesting that most consumed seeds are dispersed away from maternal trees. In this population, the genetic relatedness of seedlings was independent of distance between individuals (i.e. no SGS, Fuchs \& Hamrick 2010b). A lack of SGS likely results from dispersers mixing the progeny of multiple maternal plants or an overlap of multiple adult seed shadows (e.g. Sezen et al. 2009).

However, G. sanctum individuals may still exhibit clumped or aggregated spatial distributions in the absence of SGS via contagious seed dispersal. Birds may become "clumped dispersers" (sensu Howe 1989) if they defecate or regurgitate seeds in specific areas such as seed processing sites, display roosts, along foraging routes or in sites where predation risk is minimized (Howe \& Smallwood 1982). In PVNP, seedlings are more commonly found in areas with heavy canopy cover suggesting that seeds are more likely defecated in areas with dense canopy cover. Wheelwright (1991) has shown that birds minimize their time in foraging trees and digest in other trees to reduce predation. Most species feeding on G. sanctum have conspicuous coloration and may move to areas with dense canopy cover to reduce predation risk, thus depositing seeds in closed canopy environments.

A more likely explanation and congruent with previous genetic results, suggest that birds disperse seeds randomly and that preferential seedling germination occurs in specific spatially clumped microhabitats resulting in an aggregated distribution of seedlings. Seed germination and seedling establishment in tropical dry forests is often regulated by moisture and light (Gerhardt 1993, Ray \& Brown 1995). Research conducted in tropical dry forests in Ghana (Lieberman \& Li 1992) and Costa Rica (Gerhardt 1996) showed that moisture stress significantly increases seedling mortality during the dry season. Mortality is high in areas with high irradiance or within canopy gaps. Palo Verde has a marked dry season between December and May. Germination and establishment in open canopy areas during the wet season may result in their death during the dry season. In contrast, seedlings that germinate under shaded conditions have a higher probability of surviving during the dry season. Our results are consistent with this scenario. McLaren \& McDonald (2003) reported similar results for tropical dry forest trees in Jamaica, they showed that seedling establishment and survival was higher in heavily shaded environments, which conserved moisture. Their results were more marked for evergreen shadetolerant species, such as $G$. sanctum. Although McLaren \& McDonald (2003) showed that plants in high light environments produced more above ground biomass, this advantage could not overcome the increase in mortality caused by dehydration in these environments. Heterogeneity in the distribution of nutrients or suitable environments for germination may also generate spatially aggregated seedlings. Although we do not have information on nutrient availability, fertility is homogeneously low in the well drain shallow soils of the "Guayacan Hill" (Vaughan et al. 1982). Given the slope of the hill and precipitation regimes in PVNP, humidity is more likely to affect seedling recruitment than a patchy distribution of nutrients. Therefore we conclude that the high proportion of G. sanctum seedlings in shaded environments, which results in an aggregated distribution, is the result of greater recruitment in more mesic microhabitats. Clumped distributions arise through the combined effects of random or partially clumped seed dispersal and site-specific dry season mortality. Seedlings germinating into gaps or high radiance sites are less likely to survive the dry season, and therefore, would not occur in our censuses, which were conducted during the wet season.

Juvenile and adult $G$. sanctum are randomly distributed relative to each other, nonetheless, the average distance between adults and 
juveniles is significantly higher than between adults and other size categories. This trend has been shown for other tropical tree species (Clark \& Clark 1984, Sterner et al. 1986, Condit et al. 1992, Itoh et al. 1997, Okuda et al. 1997). Density dependent mortality (Grau 2000) and selection for specific environments (Itoh et al. 2003) have been proposed as the predominant explanations for repulsion between these two size categories. A large proportion of young individuals close to adults combined with a larger proportion of saplings and juveniles at greater distances from adults may be the result of density dependent mortality (i.e. Janzen-Connell effect, Connell 1971, Janzen 1970). However, we did not observe significant signs of herbivory or pathogen infections on $G$. sanctum seedlings or juveniles. Also, our spatial analysis shows that seedlings, saplings and juveniles are randomly distributed relative to adults with no signs of repulsion, suggesting that areas suitable for germination, establishment and growth, are randomly dispersed relative to adults. The increase in the average distance between juveniles and adults, relative to that of seedlings and adults, could be caused simply by population thinning. Therefore, biotic factors are probably not the predominant factor shaping the spatial distribution of this species.

The distribution of juveniles indicates that light availability shapes the spatial distribution of older size categories. Juveniles were predominantly found in areas with higher light availability. The environmental requirements of a species may change during development and conditions advantageous for one life stage (e.g. seedlings) may be disadvantageous for another (i.e. juveniles). While seedlings may require shade for recruitment, juveniles may require increased light availability for an extended length of time to reach maturity (Denslow 1987, Schupp 1995). Sites located near adults lack enough light for juveniles to grow, due to the dense evergreen canopy of $G$. sanctum adults. Therefore, suitable sites for growth may only become available during gap formation. Delayed gap-phase dynamics, where saplings and juveniles experience increased growth following gap formation, has been shown for many tropical rainforest trees (Denslow 1987). Gerhardt (1996) showed that for the tropical dry forest evergreen species, Hymenaea courbaril and Swietenia macrophylla, increased light availability was negatively correlated with dry season survival. Nonetheless, higher irradiance associated with canopy openings were positively correlated with high growth rates. She also showed that seedling vulnerability decreased with plant height. Therefore it is likely that once G. sanctum seedlings are established in shaded areas, they are able to develop root systems that access moisture in deeper soil strata, allowing them a more desiccation resistance. Canopy openings caused by tree falls provide juveniles with increased light regimes, which translate into higher growth rates. These gaps not only allow increased photosynthetic activity, but also signal the availability of space for saplings and juveniles to grow into the sub-adult and adult categories. As mentioned previously, all subplots have had minor to large gaps formed by tree falls within the last five to 10 years, creating the environments necessary for juvenile and sapling growth and maturation.

In conclusion, populations of $G$. sanctum in PVNP appear to be expanding due to the large number of seedlings, saplings and juveniles observed. Spatial patterns observed demonstrate that light availability due to canopy openings is an important factor shaping the spatial distribution of small plants. The demographic structure of G. sanctum is dependent on forest gap dynamics which has direct implications for its conservation. Endangered species require detailed descriptions of their life history, so that well suited management and conservation strategies can be devised to insure their future survival.

\section{ACKNOWLEDGMENTS}

The authors thank C. Alvarado and U. Chavarria from ACAT, C. Deen and D. Trapnell for laboratory assistance, G. Barrantes for bird identification, and P. Smouse and E. Gonzales 
for statistical support. Special thanks to J. Ross-Ibarra and M. Poelchau for improving previous versions of this manuscript. This work was supported by IdeaWild, Vicerrectoría de Investigación-UCR, Organization for Tropical Studies to EJF and National Science Foundation grant 0211526 to JLH.

\section{RESUMEN}

La distribución espacial es una característica fundamental de las especies y es importante para el desarrollo de estrategias de conservación y manejo. Aquí presentamos la distribución espacial de varias etapas de desarrollo del árbol tropical Guaiacum sanctum, una especie en vías de extinción. Todos los adultos de G. sanctum se geo-referenciaron en una parcela de 50ha en el Parque Nacional Palo Verde. Las plántulas, los briznales y juveniles se mapearon en tres sub-parcelas de 50x50m. En cada sub-parcela se estimó la agregación espacial de los individuos mediante la K de Ripley. Observamos que los individuos de G. sanctum se encuentran siempre agregados, sin importar en que etapa de desarrollo se encuentren. Registramos la apertura del dosel cada $5 \mathrm{~m}$ con un densiómetro y mediante una extrapolación espacial (Krigin) determinamos que las plántulas se agregan con mayor frecuencia en áreas con abundante cobertura de dosel, mientras que es más probable encontrar juveniles agregados en áreas con una mayor incidencia de luz. Las plántulas son los individuos más abundantes, esta distribución de edades nos sugiere que esta población probablemente está en expansión. Concluimos que el régimen lumínico y la cobertura de dosel son factores que afectan significativamente la distribución espacial del Guayacán Real.

Palabras clave: dinámica de claros, ornitocoria, selección de microambientes, escape a la desecación.

\section{REFERENCES}

Armesto, J.J., J.D. Mitchell \& C. Villagran. 1986. A comparison of spatial patterns of trees in some tropical and temperate forests. Biotropica 18: 1-11.

Barot, S., J. Gignoux \& J.C. Menaut. 1999. Demography of a savannah palm tree: predictions from comprehensive spatial pattern analyses. Ecology 80: 1987-2005.

Bleher, B. \& K. Bohning-Gaese. 2001. Consequences of frugivore diversity for seed dispersal, seedling establishment and the spatial pattern of seedlings and trees. Oecologia 129: 385-394.

CITES. 2000. Proposal to transfer Guaiacum sanctum from Appendix II to Apendix I of CITES. Speller \& Sons, New York, USA.
Clark, D.A. \& D.B. Clark. 1984. Spacing dynamics of a tropical rain forest tree: evaluation of the JanzenConnell model. Am. Nat. 124: 769-788.

Condit, R., P.S. Ashton, P. Baker, S. Bunyavejchewin, S. Gunatilleke, N. Gunatilleke, S.P. Hubbell, R.B. Foster, A. Itoh, J.V. Lafrankie, H.S. Lee, E. Losos, N. Manokaran, R. Sukumar \& T. Yamakura. 2000. Spatial patterns in the distribution of tropical tree species. Science 288: 1414-1418.

Condit, R., S.P. Hubbell \& R.B. Foster. 1992. Recruitment near conspecific adults and the maintenance of tree and shrub diversity in a neotropical forest. Am. Nat. 140: 261-286.

Connell, J.H. 1971. On the role of natural enemies in preventing competitive exclusion in some marine animals and in rain forest trees, p. 298-312. In P.J. van der Boer \& G.R. Gradwell (eds.). Dynamics of Numbers in Populations.Center for Agricultural Publication and Documentation, Wageningen.

Denslow, J.S. 1987. Tropical rainforest gaps and tree species diversity. Annu. Rev. Ecol. Syst. 18: 431-451.

Diggle, P. 2003. Statistical analysis of spatial point patterns. Oxford University, London, New York.

Forget, P.M., F. Mercier \& F. Collinet. 1999. Spatial patterns of two rodent-dispersed rain forest trees Carapa procera (Meliaceae) and Vouacapoua americana (Caesalpiniaceae) at Paracou, French Guiana. J. Trop. Biol. 15: 301-313.

Fuchs, E.J. \& J.L. Hamrick. 2010a. Genetic diversity in the endangered tropical tree, Guaiacum sanctum (Zygophyllaceae). J. Hered. 101: 284-291.

Fuchs, E.J. \& J.L. Hamrick. 2010b. Spatial genetic structure within size classes of the endangered tropical tree Guaiacum sanctum (Zygophyllaceae). Am. J. Bot. 97: 1200-1207.

Gerhardt, K. 1996. Effects of root competition and canopy openness on survival and growth of tree seedlings in a tropical seasonal dry forest. For. Ecol. Mang. 82: $33-48$.

Gerhardt, K. 1993. Tree seedling development in tropical dry abandoned pasture and secondary forest in Costa Rica. J. Veg. Sci. 4: 95-102.

Gilbert, G.S., S.P. Hubbell \& R.B. Foster. 1994. Density and distance-to-adult effects of a canker disease of trees in a moist tropical forest. Oecologia 98: 100-108.

Grau, H.R. 2000. Regeneration patterns of Cedrela lilloi (Meliaceae) in northwestern Argentina subtropical montane forests. J. Trop. Biol. 16: 227-242.

Greene, D.F., C.D. Canham, K.D. Coates \& P.T. Lepage. 2004. An evaluation of alternative dispersal functions for trees. J. Ecol. 92: 758-766. 
He, F.L., P. Legendre \& J.V. Lafrankie. 1997. Distribution patterns of tree species in a Malaysian tropical rain forest. J. Veg. Sci. 8: 105-114.

Holdridge, L.R. \& L.J. Poveda. 1975. Árboles de Costa Rica, Centro Científico Tropical, San José, Costa Rica.

Howe, H.F. 1989. Scatter-dispersal and clump-dispersal and seedling demography-hypothesis and implications. Oecologia 79: 417-426.

Howe, H.F. \& J. Smallwood. 1982. Ecology of seed dispersal. Ann. Rev. Ecol Syst. 13: 201-228.

Hubbell, S.P. 1979. Tree dispersion, abundance, and diversity in a tropical dry forest. Science 203: 1299-1309.

Hubbell, S.P. \& R.B. Foster. 1986. Commonness and rarity in a Neotropical forest: implications for tropical tree conservation, p. 205-231 In M.E. Soulé (ed.). Conservation Biology: The Science of Scarcity and Diversity. Sinauer, Sunderland, Massachusetts.

Hutchinson, G.E. 1953. Concept of pattern in ecology. Proc. Acad. Nat. Sci. Phil. 105: 1-12.

Ihaka, R. \& R. Gentleman. 1996. R: A language for data analysis and graphics. J. Compu. Graph. Stat. 5: 299-314.

Itoh, A., T. Yamakura, K. Ogino, H.S. Lee \& P.S. Ashton. 1997. Spatial distribution patterns of two predominant emergent trees in a tropical rainforest in Sarawak, Malaysia. Plant. Ecol. 132: 121-136.

Itoh, A., T. Yamakura, T. Ohkubo, M. Kanzaki, P.A. Palmiotto, J.V. Lafrankie, P.S. Ashton \& H.S. Lee. 2003. Importance of topography and soil texture in the spatial distribution of two sympatric Dipterocarp trees in a Bornean rainforest. Ecol. Res. 18: 307-320.

Janzen, D.H. 1970. Herbivores and the number of tree species in tropical forest. Am. Nat. 104: 501-528.

Janzen, D.H. 1988. Tropical dry forests: the most endangered major tropical ecosystem, p. 130-137 In E.O. Wilson (ed.). Biodiversity. National Academy, Washington, D.C., USA.

Jiménez, Q.M. 1993. Árboles maderables en peligro de extinción en Costa Rica. Museo Nacional de Costa Rica, San José, Costa Rica.

John, R., H.S. Dattaraja, H.S. Suresh \& R. Sukumar. 2002. Density-dependence in common tree species in a tropical dry forest in Mudumalai, Southern India. J. Veg. Sci. 13: 45-56.

Korning, J. \& H. Balslev. 1994. Growth rates and mortality patterns of tropical lowland tree species and the relation to forest structure in Amazonian Ecuador. J. Trop. Ecol. 10: 151-166.

Lambers, J.H.R., J.S. Clark \& B. Beckage. 2002. Densitydependent mortality and the latitudinal gradient in species diversity. Nature 417: 732-735.
Lieberman, D. \& M. Li. 1992. Seedling recruitment patterns in a tropical dry forest in Ghana. J. Veg. Sci. 3: $375-382$.

McLaren, K.P. \& M.A. McDonald. 2003. The effects of moisture and shade on seed germination and seedling survival in a tropical dry forest in Jamaica. For. Ecol. Manag. 183: 61-75.

Nathan, R. \& H.C. Muller-Landau. 2000. Spatial patterns of seed dispersal, their determinants and consequences for recruitment. TREE 15: 278-285.

Nichols, J.D., V.K. Agyeman, F.B. Agurgo, M.R. Wagner \& J.R. Cobbinah. 1999. Patterns of seedling survival in the tropical African tree Milicia excelsa. J. Trop. Ecol. 15: 451-461.

Okuda, T., N. Kachi, S.K. Yap \& N. Manokaran. 1997. Tree distribution pattern and fate of juveniles in a lowland tropical rain forest implications for regeneration and maintenance of species diversity. Plant. Ecol. 131: 155-171.

Oldfield, S., C. Lusty \& A. Mackinven. 1998. The world list of threatened trees. World Conservation, Cambridge, USA.

Otterstrom, S.M., M.W. Schwartz \& I. Velazquez-Rocha. 2006. Responses to fire in selected tropical dry forest trees. Biotropica 38: 592-598.

Palmiotto, P.A., S.J. Davies, K.A. Vogt, M.S. Ashton, D.J. Vogt \& P.S. Ashton. 2004. Soil-related habitat specialization in Dipterocarp rain forest tree species in Borneo. J. Ecol. 92: 609-623.

R Development Core Team. 2008. R: A Language and Environment for Statistical Computing.Vienna, Austria. Available at: http://www.R-project.org.

Ray, G.J. \& B.J. Brown. 1995. Restoring Caribbean dry forests: evaluation of tree propagation techniques. Res. Ecol. 3: 86-94.

Ribeiro, P.J.J. \& P.J. Diggle. 2001. GeoR: a package for geostatistical analysis. R-NEWS 1: 14-18.

Ripley, B.D. 1977. Modeling spatial patterns. J. Roy. Stat. Soc. B. 39: 172-212.

Ripley, B.D. 1976. The second-order analysis of stationary point processes. J. App. Prob. 13: 255-256.

Russo, S.E. \& C.K. Augspurger. 2004. Aggregated seed dispersal by spider monkeys limits recruitment to clumped patterns in Virola calophylla. Ecol. Lett. 7: 1058-1067.

Sagar, R. \& J.S. Singh. 2004. Local plant species depletion in a tropical dry deciduous forest of northern India. Environ. Conserv. 31: 55-62.

Schupp, E.W. 1995. Seed seedling conflicts, habitat choice, and patterns of plant recruitment. Am. J. Bot. 82: 399-409. 
Schupp, E.W. 1992. The Janzen-Connell model for tropical tree diversity: Population implications and the importance of spatial scale. Am. Nat. 140: 526-530.

Sezen, U.U., R.L. Chazdon \& K.E. Holsinger. 2009. Proximity is not a proxy for parentage in an animaldispersed neotropical canopy palm. P. Roy. Soc. Lond. B. 276: 2037-2044.

Silla, F., S. Fraver, A. Lara, T.R. Allnutt \& A. Newton. 2002. Regeneration and stand dynamics of Fitzroya cupressoides (Cupressaceae) forests of southern Chile's Central Depression. For. Ecol. Manag. 165: 213-224.

Slik, J.W.F. \& K.A.O. Eichhorn. 2003. Fire survival of lowland tropical rain forest trees in relation to stem diameter and topographic position. Oecologia 137: 446-455.

Souza, A.F. \& F.R. Martins. 2004. Microsite specialization and spatial distribution of Geonomabrevispatha, a clonal palm in south-eastern Brazil. Ecol. Res. 19: 521-532.

Sterner, R.W., C.A. Ribic \& G.E. Schatz. 1986. Testing for life historical changes in spatial patterns of four tropical tree species. J. Ecol. 74: 621-633.
Turner, R. \& A. Baddeley. 2005. Spatstat: An R package for analysing spatial point patterns. J. Stat. Software. 12: $1-42$.

Vaughan, C., G. Canessa, M. McCoy, J. Rodriguez, J. Sánchez, R. Morales, T. Hawkins, E. Crozier, D. Shaffer, M. Rodriguez \& F. Hodgson. 1982. Refugio de fauna Silvestre Rafael Lucas Caballero. Plan de Manejo. Editorial UNA, Heredia, Costa Rica.

Voeks, R.A. 2004. Disturbance pharmacopoeias: medicine and myth from the humid tropics. Ann. Assoc. Am. Geogr. 94: 868-888.

Wendelken, P. \& R. Martin. 1987. Avian consumption of Guaiacum sanctum fruit in the arid interior of Guatemala. Biotropica 19: 116-121.

Wheelwright, N.T. 1991. How long do fruit-eating birds stay in the plants where they feed? Biotropica 23: 29-40.

Yamada, T. \& E. Suzuki. 1997. Changes in spatial distribution during the life history of a tropical tree, Scaphiummacropodum (Sterculiaceae) in Borneo. J. Plant. Res. 110: 179-186.

Zuidema, P.A. \& R.G.A. Boot. 2002. Demography of the Brazil nut tree (Bertholletia excelsa) in the Bolivian Amazon: impact of seed extraction on recruitment and population dynamics. J. Trop. Ecol. 18: 1-31. 
